Original Research Paper

\title{
Clinical and Epidemiological Characteristics of New Cases of HIV/AIDS Identified between 2011-2016 at a Tertiary Hospital, in Mexico City
}

\author{
Enrique Alcalá Martínez, Verónica Alejandra Gaona Flores, \\ Paz Ayar Nibardo and Guevara Iturriaga Samanta \\ Infectious Diseases Hospital, Centro Médico Nacional La Raza, Mexico City, Mexico
}

\author{
Article history \\ Received: 29-03-2018 \\ Revised: $16-07-2018$ \\ Accepted: 1-09-2018 \\ Corresponding Author: \\ Verónica Alejandra Gaona \\ Flores \\ Infectious Diseases Hospital, \\ Centro Médico Nacional La \\ Raza, Mexico City, Mexico \\ Tel: 5556337337 \\ Email: vgaona2@yahoo.com.mx
}

\begin{abstract}
Nowadays, HIV infections and AIDS cases are on the increase in Africa, Asia, Latin America and the Caribbean. The associated risk factors for developing AIDS have been: Alcoholism, drug use, malnutrition, comorbidities and semi-illiteracy. The objective of the study was to describe the clinical and epidemiological characteristics of new cases of HIV/AIDS and to look for the possible factors associated with AIDS in patients treated at a tertiary hospital in Mexico City. A descriptive, retrospective study conducted from 2011 to 2016 that included new cases of HIV/AIDS in patients that were admitted for the first time to a third-level medical unit in Mexico City. In all cases, Enzyme-Linked Immunoenzymatic Assays were performed (EIA), Western Blot test, viral load, CD4 lymphocyte count, viral panel for Hepatitis B, C, Herpes Simplex Virus (HSV) and other viruses were investigated. The male gender was the predominant with $87.5 \%$, the average age was 32.3 years and most of them just have the basic education. Regarding sexual preference, $60 \%$ fall into the category of men who have sex with men. Some of the identified risk factors associated with AIDS include: Co-infection with (HSV) and tuberculosis (RMP 4.61 and 2.24, respectively), patients with antiretroviral treatment initiation (RMP 1.41) and viral load with more than 100,000 copies (RMP 3.18). Risk factors associated with AIDS that are found in the population studied include: Coinfection and educational level which are similar to that reported in several studies, although, it is not applicable to the rest of the factors found. The timely identification of this disease is of great importance to avoid, as much as possible, its advancement to the stage of AIDS, with the intention of avoiding complications, reducing mortality and reducing the high costs that this pathology generates.
\end{abstract}

Keywords: Human Immunodeficiency Virus, HIV, Acquired Immunodeficiency Syndrome, AIDS, Risk Factors

\section{Introduction}

Throughout the history of humanity, diseases have played a special role in the development of societies. The epidemy of Human Immunodeficiency Virus (HIV) and the Acquired Immune Deficiency Syndrome (AIDS) began in Latin America and the Caribbean at different times. AIDS, one of the most recently described diseases, has undoubtedly had a great impact on modern life. Prior to this time, it was observed that the cause of this epidemic was determined by some biological, social and behavioral factors. AIDS increases the burden on health services and use up the already limited financial resources. The majority of HIV infections and AIDS cases are occurring in regions with low human development index: Africa, Asia, Latin America and the Caribbean. Recently, the epidemic has gained momentum in the new independent states of the 
former Soviet Union. The prevalence of HIV infection is unevenly distributed all over the world: While the highest estimated prevalence among adults was recorded in Sub-Saharan Africa (7.4\%), Western Asia and the Pacific have an estimated prevalence of $0.05 \%$; Latin America has $0.5 \%$ and the Caribbean has $1.9 \%$ of prevalence. In Colombia, Venezuela and Mexico, the epidemy is concentrated in men who have sex with men and bisexuals. In Central America and the Caribbean, it occurs mainly in heterosexuals, while in Argentina and Brazil, there is a growing proportion of cases among intravenous drug users (Astarloa et al., 1998).

According to estimates made by Censida (National Center for the prevention and control of HIV and AIDS in Mexico), at the end of 2013, there were 180,000 people living with HIV and AIDS. The prevalence of HIV in the population for over 15 years was $0.2 \%$ (VIH, 2018). Most of the studies reported that a significant number of HIV cases occurred in people between 15 and 35 years of age, which suggest that a large part of this population group was probably infected before the age of 20 . As a result, the period of sero conversion may take months, that is, after the acute phase and before the period of chronic symptomatic infection, several years may pass until the diagnosis is made.

Risk groups have been identified to contract the infection, among which adolescents stand out (when most of them begin their sexual life) because they are mostly affected, especially by being exposed to a large number of risk factors such as: Sexual intercourse without condoms, promiscuity, greater consumption of alcohol and drugs and inadequate or deficient knowledge, among others. Hence, the need to consider young people as agents of change in developing preventive strategies (Navarro and Vargas, 2005). Among the risk factors for developing AIDS, an association has been found between comorbidities with a risk of 7.9, low schooling having 2.6 times more risk, toxic habits (alcoholism, smoking, drug use) increases the risk of developing AIDS by 16.2 times, just as malnutrition increases the risk by 10.3 times. Three decades have passed since the first cases of HIV/AIDS in Mexico, primary prevention has been carried out in young people, the country has access to all antiretrovirals, however, the epidemic in Mexico is still springing up new cases of HIV/AIDS (13,883 cases reported in the first quarter of 2018), RNCSIDA (2018) a circumstance that suggests the epidemiological aspects of these cases have changed so much compared to the previous stages of this pathology. The question is: Does tuberculosis remain one of the main coinfections that the risk factors remain the same?
The aim of the present study was to describe the clinical and epidemiological characteristics of new cases of HIV/AIDS, as well as to look for possible factors associated with AIDS in patients treated in a tertiary hospital in Mexico City.

\section{Materials and Methods}

A descriptive and retrospective study was conducted from January 2011 to April 2016 in a third level hospital in Mexico City. The inclusion criteria are all patients with a new diagnosis of HIV/AIDS, identified within this period and admitted at the medical unit for the first time as well as those whose information about epidemiological surveillance are available in the hospital records. In all cases, an epidemiological study was carried out, which includes social, demographic, epidemiological and clinical data and the diagnosis was confirmed with laboratory studies through EIA and Western Blot test, also performing CD4 lymphocytes, viral load and serology to identify associated infections.

For the statistical analysis, relative frequencies were calculated for the nominal variables and measures of central tendency and dispersion for the quantitative variables, as well as the Kolmogorov-Smirnov test to know the distribution. To find the association of risk factors for AIDS, we calculated the Prevalence Moment Ratio (RMP), 95\% Confidence Intervals (95\% $\mathrm{CI}), \mathrm{X} 2$ and $\mathrm{p} \leq 0.05$ values.

\section{Results}

The authors during the period of this study identified that there were 1,432 patients diagnosed with HIV/AIDS, predominantly male with $87.5 \%$. The mean age was 32.34 years. For CD4 lymphocytes, the average was 209.91 cells $/ \mathrm{mm}^{3}$ and for the viral load, an average of $368,467.29$ was found. The age group in which the disease predominated was between 18 to 44 years $(85.5 \%)$ and being single was the most frequent marital status (75.2\%). Basic schooling (studies completed up to preparatory level or equivalent) was the highest proportion (62.5\%), with Mexico City being the place of birth $(52.1 \%)$ and the most common residence (54.2\%) than the population studied (Table 1).

Among the epidemiological antecedents of the patients, it can be observed that the sexual preference of greater frequency was that of the Men that had Sex with Men $(60.2 \%)$. About $3.1 \%$ of the cases were blood donors with a history of transfusions (Table 2).

Hepatitis B (3.8\%) and Herpes Simplex Virus (HSV) (4.6\%) were found among the most frequently associated pathologies. Only $31.1 \%$ of the patients initiated antiretroviral treatment at the time of diagnosis and $41.3 \%$ were in the HIV phase. In 2013, the highest 
number of cases was observed (631), while in 2011, the lowest frequency was observed (Table 3 ).

In the bivariate analysis, it was found that the lower the educational level, the greater the risk of AIDS, although, it was not statistically significant. Having a history of receiving transfusions increases the risk by 2.2 times, coinfections with (HSV) and tuberculosis increase the risk of developing AIDS 4.1 and 2.7 times, respectively. Just as having a viral load equal to or greater than 100, 000 copies, the risk increases 3 times at $\mathrm{p} \leq 0.05$ (Table 4 ).

In the multivariate analysis adjusted for age, sex, occupation and schooling, an association was found between coinfection with (HSV) (RMP 4.61), tuberculosis (RMP 2.24), receiving antiretroviral treatment (RMP 1.41) and viral load equal to or greater than 100,000 copies (RMP). 3.18), which is statistically significant $(\mathrm{p} \leq 0.05)$ (Table 5).

Table 1: Social and demographic characteristics of patients

\begin{tabular}{lrr}
\hline Variable & Number & \multicolumn{1}{c}{$\%$} \\
\hline Sex & & \\
Male & 1253 & 87.5 \\
Female & 179 & 12.5 \\
Age & & \\
Under 18 years old & 21 & 1.5 \\
18 to 44 years & 1225 & 85.5 \\
45 to 59 years & 156 & 10.9 \\
60 and more years & 30 & 2.1 \\
Civil Status & & \\
Single & 1077 & 75.2 \\
Married & 158 & 11.0 \\
Free Union & 144 & 10.1 \\
Other & 53 & 3.7 \\
Scholarship & & \\
Without schooling & 13 & 0.9 \\
Basic schoooling & 891 & 62.2 \\
Higher schooling & 513 & 35.8 \\
Pos grade & 15 & 1.0 \\
Occupation & & \\
Without occupation & 83 & 5.8 \\
activities of their profession & 229 & 16.0 \\
activities not specific to their profession & 962 & 67.2 \\
Student & 136 & 9.5 \\
Retired/pensioner & 22 & 1.5 \\
Place of birth & & \\
Mexico City & 746 & 52.1 \\
State of Mexico & 323 & 22.6 \\
Veracruz & 60 & 4.2 \\
Puebla & 45 & 3.1 \\
Oaxaca & 44 & 3.1 \\
other state & 206 & 14.3 \\
Other country & 876 \\
Place of residence & & \\
Mexico City & 601 & 54.2 \\
State of Mexico & 42.0 \\
Hidalgo & 1.0 \\
Other state & 2.8 \\
\hline & & \\
\hline
\end{tabular}

Table 2: Patients' pathological and non-pathological background

\begin{tabular}{lrr}
\hline Variable & Number & \multicolumn{1}{c}{$\%$} \\
\hline Indigenous race & 2 & \\
Yes & 1430 & 0.1 \\
No & & 99.9 \\
Speak indigenous language & 5 & \\
Yes & 1427 & 0.3 \\
No & & 99.7 \\
Has had children in the past 2 years & 25 & \\
Yes & 1407 & 1.7 \\
No & & 98.3 \\
Sexual Preference & 862 & \\
Men who have Sex with Men & 177 & 60.2 \\
Bisexual & 382 & 12.4 \\
Heterosexual & 11 & 26.7 \\
Not mentioned & & 0.8 \\
Commercial sex worker & 7 & \\
Yes & 1425 & 0.5 \\
No & & 99.5 \\
Blood transfusions & 45 & 3.1 \\
Yes & 1387 & 96.9 \\
No & & \\
You have hemophilia & 3 & 0.2 \\
Yes & 1429 & 99.8 \\
No & & \\
Injecting drug user & 6 & 0.4 \\
Yes & 1426 & 99.6 \\
No & & \\
Blood donor & 44 & 3.1 \\
Yes & 1388 & 96.9 \\
No & & \\
Organ transplant recipient & 2 & 0.1 \\
Nes & & \\
\hline & & \\
\hline
\end{tabular}

Table 3: Presence of comorbidities and stage of the disease

\begin{tabular}{lrr}
\hline Variable & Number & \% \\
\hline Hepatitis B coinfection & & \\
Yes & 55 & 3.8 \\
No & 1377 & 96.2 \\
Hepatitis C coinfection & 17 & \\
Yes & 1415 & 1.2 \\
No & & 98.8 \\
Herpes simplex virus coinfection & 66 & \\
Yes & 1366 & 4.6 \\
No & & 95.4 \\
Tuberculosis coinfección & 39 & \\
Yes & 1393 & 2.7 \\
No & & 97.3 \\
Antiretroviral treatment & 446 & \\
Yes & 986 & 31.1 \\
No & & 68.9 \\
Viral Load & 746 & \\
More than 100,000 copies & 686 & 52.1 \\
Less than 100,000 copies & & 47.9 \\
Clinical category & 840 & \\
AIDS & 592 & 58.7 \\
HIV & & 41.3 \\
Year of diagnosis & 132 & \\
2011 & 168 & 9.2 \\
2012 & 631 & 41.7 \\
2013 & 201 & 14.0 \\
2014 & 232 & 16.2 \\
2015 & 68 & 4.7 \\
$2016 *$ & & \\
*Cut to the month of April 2016 & &
\end{tabular}


Enrique Alcalá Martínez et al. / American Journal of Infectious Diseases 2018, 14 (2): 57.62 DOI: 10.3844/ajidsp.2018.57.62

Table 4: Bivariate analysis of factors associated with AIDS

\begin{tabular}{|c|c|c|c|c|}
\hline Variable & RMP & IC 95\% & $X^{2}$ & $\mathrm{P}$ \\
\hline \multicolumn{5}{|l|}{ Sex } \\
\hline Male & 1.08 & $0.78,1.48$ & 0.230 & 0.620 \\
\hline Female & 1.00 & & & \\
\hline \multicolumn{5}{|l|}{ Occupation } \\
\hline Related to her profession & 0.75 & $0.43,1.33$ & 0.900 & 0.340 \\
\hline Not related to your profession & 0.50 & $0.30,0.84$ & 6.940 & 0.008 \\
\hline Student & 0.48 & $0.26,0.88$ & 5.490 & 0.010 \\
\hline Retired & 0.68 & $0.06,7.71$ & 0.090 & 0.750 \\
\hline Pensioned & 0.54 & $0.18,1.63$ & 1.160 & 0.280 \\
\hline Without occupation & 1.00 & & & \\
\hline \multicolumn{5}{|l|}{ Scholarship } \\
\hline Without schooling & 4.67 & $0.81,26.96$ & 2.970 & 0.080 \\
\hline Basic education & 1.46 & $0.48,4.44$ & 0.440 & 0.500 \\
\hline Higher education & 1.49 & $0.48,4.58$ & 0.500 & 0.470 \\
\hline Posgraduate & 1.00 & & & \\
\hline \multicolumn{5}{|c|}{ Has had children in the past 2 years } \\
\hline Yes & 1.83 & $0.75,4.41$ & 0.170 & 0.220 \\
\hline No & 1.00 & & & \\
\hline \multicolumn{5}{|l|}{ Commercial sex worker } \\
\hline Yes & 1.76 & $0.34,9.13$ & 0.490 & 0.700 \\
\hline No & 1.00 & & & \\
\hline \multicolumn{5}{|l|}{ Transfusions } \\
\hline Yes & 2.22 & $1.12,4.43$ & 0.010 & 0.020 \\
\hline No & 1.00 & & & \\
\hline \multicolumn{5}{|l|}{ Hepatitis B coinfection } \\
\hline Yes & 1.46 & $0.82,2.60$ & 0.180 & 0.210 \\
\hline No & 1.00 & & & \\
\hline \multicolumn{5}{|l|}{ Herpes simplex virus coinfection } \\
\hline Yes & 4.15 & $2.10,8.21$ & $<0.001$ & $<0.001$ \\
\hline No & 1.00 & & & \\
\hline \multicolumn{5}{|l|}{ Tuberculosis coinfection } \\
\hline Yes & 2.79 & $1.27,6.13$ & 0.007 & 0.008 \\
\hline No & 1.00 & & & \\
\hline \multicolumn{5}{|l|}{ Antiretroviral treatment } \\
\hline Yes & 1.51 & $1.20,1.91$ & $<0.001$ & $<0.001$ \\
\hline No & 1.00 & & & \\
\hline \multicolumn{5}{|l|}{ Viral load } \\
\hline More than 100,000 copies & 3.01 & $2.42,3.74$ & $<0.001$ & $<0.001$ \\
\hline Less than 100,000 copies & 1.00 & & & \\
\hline
\end{tabular}

Table 5: Multivariate analysis of factors associated with AIDS*

\begin{tabular}{|c|c|c|c|c|}
\hline & RMP & IC 95\% & $\mathrm{X}^{2}$ & $\mathrm{P}$ \\
\hline \multicolumn{5}{|l|}{ Sex } \\
\hline Male & 1.23 & $0.83,1.82$ & 1.14 & 0.28 \\
\hline Female & 1.00 & & & \\
\hline \multicolumn{5}{|c|}{ Herpes simplex virus Coinfection } \\
\hline Yes & 4.61 & $2.26,9.40$ & 22.60 & $<0.001$ \\
\hline No & 1.00 & & & \\
\hline \multicolumn{5}{|l|}{ Tuberculosis coinfection } \\
\hline Yes & 2.24 & $0.97,5.18$ & 4.00 & 0.05 \\
\hline No & 1.00 & & & \\
\hline \multicolumn{5}{|l|}{ Antiretroviral treatment } \\
\hline Yes & 1.41 & $1.09,1.83$ & 7.26 & 0.007 \\
\hline No & 1.00 & & & \\
\hline \multicolumn{5}{|l|}{ Viral load } \\
\hline More than 100,000 copies & 3.18 & $2.53,4.00$ & 104.05 & $<0.001$ \\
\hline Less than 100,000 copies & 1.00 & & & \\
\hline
\end{tabular}

*Adjusted for age, sex, occupation and schooling 


\section{Discussion}

For the group of patients studied during the six-year period, it was found that the risk factors for AIDS in this group were coinfection with (HSV) and tuberculosis, not receiving antiretroviral treatment and having a viral load with more than 100,000 copies.

In a previous study (Castillo, 2012), the mean age of patients which is 29.9 years was found similar to what was observed in our study being 32.3 years, a similar situation in relation to schooling which was basic education in both studies (Castillo et al., 2012).

In our research, infections associated with AIDS were (HSV) and tuberculosis. Other authors have reported that the risk factors for AIDS is by having related infections, without specifying data on the infection (Castro et al., 2014), In the same study, the low educational level was associated with AIDS, finding a similar result in our research, where the risk increases in those patients not schooling. Although, in our study, $\mathrm{P}$ value was not significant.

A fundamental aspect is HIV viral load equal to or greater than 100,000 copies of RNA, which together with coinfections increase the risk of developing AIDS. In these circumstances, tuberculosis that shows the persistence in the increase of incidence and prevalence in the country, leads to the risk of resistance to specific treatments, similar to what occurred in other undeveloped countries (TBC-VIH/SIDA, 2017); not forgetting that the cases of AIDS and untreated tuberculosis are a factor that increases the transmission of infection by tuberculosis bacillus to the general population (Laguardia and Merchan-Hamann, 2003). CNS tuberculosis in its meningeal, tuberculoma or abscess varieties has been reported in a neurological care institution in $11.3 \%$ of its cases treated in a 6-year review (Velasquez-Perez and Ramirez-Crescencio, 2011). In Mexico, diagnostic tests for HIV are performed and there is access to antiretroviral treatment, without the patient having to pay for this. However, the evolution to severe forms of the disease continues to be frequent in the Mexican population (PAUTAM, 2018).

Epidemiological studies such as this research have proposed the identification of factors that contribute to increase the problems related to the characteristics of a population with HIV and to the factors associated with the evolution towards AIDS. Among them are those related to the quality of life, a circumstance that is related to social security and costs in this regard. Although a decrease in the number of cases of HIV/AIDS has been identified in recent years, compared to the first years of the epidemic in Mexico, it is necessary to know the clinical and epidemiological characteristics of people diagnosed as new cases of infection by HIV, to establish prevention strategies and help reduce the incidence of HIV infection, which is also sought with respect to AIDS. It is important to consider serology studies for viral infections, Rubella, Cytomegalovirus, Herpes simplex and Varicella zoster; for bacteria as in the case of syphilis and parasitic as toxoplasmosis; of imaging, such as chest x-ray, studies that are part of the clinical and epidemiological framework of the person treated with HIV infection in Mexico.

The results of this study allowed us to identify and describe factors that are not new, which coincide with other publications, already identified and related as risk factors, which are still useful for monitoring and controlling the strategies applied in the population with and in risk in countries considered to have a high prevalence of HIV infection; where often, carriers of the virus are unaware of their status until opportunistic infections appear.

\section{Conclusion}

HIV continues to pose a challenge in public health, as reported by various health agencies, of which the number of cases has decreased in recent years. While it is true that the advancement in technology and research has produced new drugs that increase the hope and quality of life of these patients, it is essential to reassess the strategies for their prevention, in order to consistently minimize the incidence of the disease.

In the same way, it is very important to avoid as much as possible the advancement of this disease to the AIDS stage with the intention of avoiding complications, reducing mortality and reducing the high costs that this pathology generates.

In the last 15 years, an important global advancement in response to this virus (HIV) has been observed (ONUSIDA, 2016).

\section{Acknowledgment}

Thanks Dr. José Arellano Galindo, for his invaluable support in the revision and correction of this work.

\section{Author's Contributions}

Enrique Alcalá Martínez: Conception and design of hte idea, analysis and interpretation of data, writing of the manuscript.

Verónica Alejandra Gaona Flores: Conception and design of the idea, interpretation of data, writing of the manuscript. 
Paz Ayar Nibardo: Collection and interpretation of data.

Guevara Iturriaga Samanta: Data collection and interpretation of data.

\section{Ethics}

This investigation is without risk, data of files were obtained.

\section{References}

Astarloa, L., F.C. Ávila, P.F. Bronfman, C. Cabezudo and P.C. Cáceres et al., 1998. Situación Epidemiológica y Económica del SIDA en América Latina y el Caribe. 1st Edn., Fundación Mexicana Para la Salud, pp: 404.

Castillo, M.J., A. Allshouse, C. Collins, T.M. Hastings and T.B. Campbell et al., 2012. Differences in sexual risk behavior and HIV/AIDS risk factors among foreign-born and us-born Hispanic women. J. Immigrant Minority Health, 14: 89-99. DOI: $10.1007 / \mathrm{s} 10903-011-9529-7$

Castro, R.A., F.E. Santana, B.J. Lemes, T.I. Arias and F.R. Rosabal, 2014. Factores de riesgo y sida en personas diagnosticadas con VIH. Granma. Multimed., 18: 1-17.

Laguardia, J. and E. Merchan-Hamann, 2003. Factores de riesgo para la enfermedad tuberculosa en los casos de SIDA notificados en Brasil, 1980-2000. Rev. Esp. Salud Pub., 77: 553-565.
Navarro, L.E. and M.R. Vargas, 2005. Factores de riesgo para adquirir VIH/SIDA en adolescentes escolarizados de Barranquilla, 2003. Invest. Educ. Enferm., 23: 44-53.

ONUSIDA, 2016. Informe de brechas en prevención. UNAIDS.

PAUTAM, 2018. Programa de acceso universal al tratamiento antirretroviral en México. https://www.gob.mx/censida/acciones-yprogramas/programa-de-acceso-universal-altratamiento-antirretroviral

RNCSIDA, 2018. Vigilancia Epidemiológica de Casos de VIH/SIDA en México, Registro Nacional de Casos de SIDA. Actualización al 3er trimestre del.

TBC-VIH/SIDA, 2017. TBC-VIH/SIDA.

Velasquez-Perez, L. and M.A. Ramirez-Crescencio, 2011. Enfermedades neurológicas de vigilancia y notificación obligatoria: Tendencia y desenlace en un Instituto Neurológico del Sistema Nacional de Salud de la Ciudad de México, de 2005-2011. Gac. Med. Mex., 150: 540-551

VIH, 2018. La epidemia del VIH y el sida en México. www.censida.salud.gob.mx/descargas/epidemiologi a/L_E_V_S.pdf 